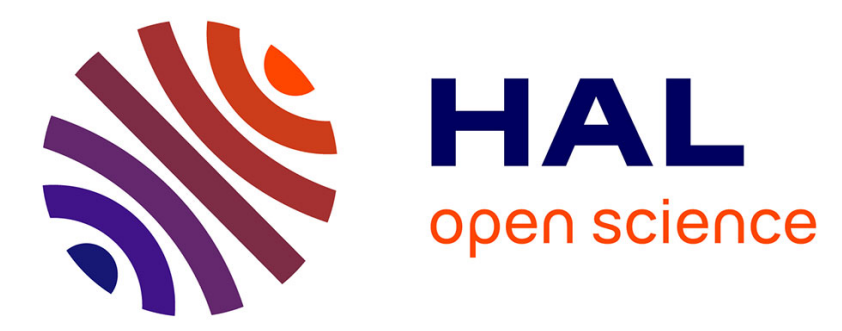

\title{
Present-day genetic composition suggests contrasting demographic histories of two dominant chaetognaths of the North-East Atlantic, Sagitta elegans and S. setosa
} K T C A Peijnenburg, E K van Haastrecht, Cécile Fauvelot

\section{- To cite this version:}

K T C A Peijnenburg, E K van Haastrecht, Cécile Fauvelot. Present-day genetic composition suggests contrasting demographic histories of two dominant chaetognaths of the North-East Atlantic, Sagitta elegans and S. setosa. Marine Biology, 2005, 147, pp.1279 - 1289. 10.1007/s00227-005-0041-2 . ird03044192

\author{
HAL Id: ird-03044192 \\ https://hal.ird.fr/ird-03044192
}

Submitted on 7 Dec 2020

HAL is a multi-disciplinary open access archive for the deposit and dissemination of scientific research documents, whether they are published or not. The documents may come from teaching and research institutions in France or abroad, or from public or private research centers.
L'archive ouverte pluridisciplinaire HAL, est destinée au dépôt et à la diffusion de documents scientifiques de niveau recherche, publiés ou non, émanant des établissements d'enseignement et de recherche français ou étrangers, des laboratoires publics ou privés. 


\section{Present-day genetic composition suggests contrasting demographic histories of two dominant chaetognaths of the North-East Atlantic, Sagitta elegans and S. setosa}

Received: 25 October 2004/ Accepted: 23 May 2005 / Published online: 14 July 2005

(C) Springer-Verlag 2005

\begin{abstract}
Sagitta elegans and S. setosa are the two dominant chaetognaths in the North-East (NE) Atlantic. They are closely related and have a similar ecology and life history, but differ in distributional ranges. $\mathrm{Sa}$ gitta setosa is a typical neritic species occurring exclusively above shelf regions, whereas $S$. elegans is a more oceanic species with a widespread distribution. We hypothesised that neritic species, because of smaller and more fragmented populations, would have been more vulnerable to population bottlenecks resulting from range contractions during Pleistocene glaciations than oceanic species. To test this hypothesis we compared mitochondrial Cytochrome Oxidase II DNA sequences of $S$. elegans and $S$. setosa from sampling locations across the NE Atlantic. Both species displayed very high levels of genetic diversity with unique haplotypes for every sequenced individual and an approximately three times higher level of nucleotide diversity in S. elegans (0.061) compared to $S$. setosa (0.021). Sagitta setosa mitochondrial DNA (mtDNA) haplotypes produced a star-like phylogeny and a uni-modal mismatch distribution indicative of a bottleneck followed by population expansion. In contrast, $S$. elegans had a deeper mtDNA phylogeny and a multi-modal mismatch distribution as would be expected from a more stable population. Neutrality tests indicated that assumptions of the standard neutral model were violated for both species and results from the McDonald-Kreitman test suggested that selection played a role in the evolution of their mitochondrial DNA. Congruent with these results, both species had much smaller effective population sizes
\end{abstract}

Communicated by O. Kinne, Oldendorf/Luhe

K. T. C. A. Peijnenburg $(\bowtie) \cdot$ E. K. van Haastrecht · C. Fauvelot Institute for Biodiversity and Ecosystem Dynamics,

Faculty of Science, Universiteit van Amsterdam,

P.O. Box 94062, 1090 GB, Amsterdam, The Netherlands

E-mail: peijnenburg@science.uva.nl

Tel.: + 31-20-5257761

Fax: $+31-20-5257878$ estimated from genetic data when compared to census population sizes estimated from abundance data, with a factor of $\sim 10^{8}-10^{9}$ difference. Assuming that selective effects are comparable for the two species, we conclude that the difference in genetic signature can only be explained by contrasting demographic histories. Our data are consistent with the hypothesis that in the NE Atlantic, the neritic $S$. setosa has been more severely affected by population bottlenecks resulting from Pleistocene range shifts than the more oceanic $S$. elegans.

\section{Introduction}

Comparison of the population genetic composition of closely related species can be a powerful approach to investigate the importance of contrasting life history and ecological characteristics on a species' evolutionary history. Several studies have used this approach with marine fish (e.g., Arnaud et al. 1999; Dudgeon et al. 2000; Fauvelot et al. 2003), but to our knowledge only one study has used this approach with zooplankton (Bucklin and Wiebe 1998). In that study the genetic composition of two planktonic copepods with different distributions, and different ecological and life history traits was compared, and results indicated that different levels of genetic diversity may be a legacy of contrasting effects of Pleistocene glaciations. Planktonic taxa are ideal for such comparative approaches because, by definition, they are unable to swim against major ocean currents (Van der Spoel and Heyman 1983) and hence, do not exhibit confounding differences in behaviour that often hamper comparisons of the impact of climatic shifts on a species' evolutionary history.

Chaetognaths are found in many marine habitats from coastal waters to the open seas. They are often highly abundant and are functionally very important in marine food webs (Bone et al. 1991). Sagitta elegans Verrill, 1873 and S. setosa Müller, 1847 are the two 
dominant planktonic chaetognaths in the North-East (NE) Atlantic, and based on morphological and genetic evidence, appear to be very closely related. A recent revision of the phylum Chaetognatha placed the two species in the same genus 'Parasagitta' based on morphological similarities (Bieri 1991), and a molecular phylogeny based on 28S ribosomal DNA sequences indicated a sister species relationship (Telford and Holland 1997).

Sagitta elegans and $S$. setosa have similar ecological characteristics. They are both active predators on other zooplankton (mainly copepods) and demonstrate little dietary differentiation. Differences that have been observed mainly reflect differences in size $(S$. setosa is smaller and takes smaller prey) and prey availability associated with vertical distribution $(S$. setosa occurs higher in the water column, Øresland 1987; Feigenbaum 1991). The two species also have similar life histories. Like all chaetognaths they are protandrous hermaphrodites (testes mature before the ovaries), and reproduction is with internal fertilisation occurring while eggs are in the ovary (Pearre 1991). Cross-fertilisation is believed to be the rule in nature, although self-fertilisation has been observed in the laboratory (Alvariño 1965; Dallot 1968). Eggs of S. elegans and S. setosa are released in the sea and remain in the open water column (Pearre 1991) and both species can lay several batches, sometimes over prolonged periods (Dallot 1968; Jakobsen 1971). This, together with evidence that different cohorts may be transported from elsewhere into a particular region, has made it difficult to estimate the number of breeding cycles per year. It has been suggested that $S$. elegans has between one and five, and $S$. setosa has between one and six breeding cycles in the NE Atlantic, with the number generally increasing southwards (reviewed in Pearre 1991). However, Jakobsen (1971) and Øresland (1983; 1986) criticised Russell's (1932a, b) findings of multiple (five or six) breeding cycles in the English Channel and concluded that there is no conclusive evidence for more than a single generation per year, and that the number of cycles of S. elegans and $S$. setosa in different regions of the NE Atlantic should be regarded as an open question.

The main difference between $S$. elegans and S. setosa is related to their habitat preferences. Traditionally, the two species have been regarded as useful indicators of different water masses in the NE Atlantic, with S. elegans characterising the inflow of oceanic water and S. setosa characterising coastal water (e.g., Meek 1928; Russell 1939; Fraser 1952; Bainbridge 1963). This difference is also reflected in their distributions. Sagitta elegans has an extensive cold-water distribution, occurring in the upper $100-150 \mathrm{~m}$ in Arctic and Subarctic regions, and extending into the northern parts of the Atlantic and Pacific oceans (Fig. 1a, Alvariño 1965; Pierrot-Bults and Nair 1991). The species is sometimes referred to as 'distant neritic' because it usually has denser populations in nearshore areas (Tokioka 1979; Pierrot-Bults and Van der Spoel 2003). Sagitta setosa has a more restricted distribution with disjunct populations above continental shelf areas in the NE Atlantic, Mediterranean Sea, and Black Sea (Fig. 1a, Alvariño 1965; Peijnenburg et al. 2004). Thus, S. setosa can be regarded as a typically neritic species and $S$. elegans as a more oceanic one.

Neritic species, because of smaller and more fragmented populations are potentially more vulnerable to population bottlenecks resulting from climate-induced range shifts and compressions than more widely distributed oceanic species (Angel 1993; Grant and Bowen 1998; Arnaud et al. 1999). In a recent study of mitochondrial diversity of $S$. setosa populations from the NE Atlantic, Mediterranean, and Black Sea (Peijnenburg et al. 2004), it was shown that although levels of diversity were very high, there was significant evidence of population bottlenecks, particularly in the NE Atlantic and Black Sea. During Pleistocene glacials, the NE Atlantic was covered with land ice and polar desert (Andersen and Borns 1994) and was therefore not habitable for marine plankton. Since $S$. elegans and $S$. setosa presently cooccur in the NE Atlantic, have a similar life history, and are closely related species, they provide a unique opportunity to compare the effect of differences in distributional range on the genetic impact of Pleistocene glaciations. Population size changes leave detectable patterns in the population genetic composition of species, which can be revealed by DNA sequencing and is called a genetic signature. For example, the distribution of nucleotide differences between all pairs of non-recombining sequence, such as mitochondrial DNA, is called a mismatch distribution. Population expansions produce a wave in this distribution creating a uni-modal pattern. By contrast, multi-modal distributions are expected for samples drawn from populations with constant population sizes (Slatkin and Hudson 1991; Rogers and Harpending 1992). Also, the amount of genetic diversity within a population can provide information about the evolutionary effective population size and thus about a species' demographic history.

In this paper, we present DNA sequence data from the same mitochondrial fragment for S. elegans as for $S$. setosa (published in Peijnenburg et al. 2004) and compare the genetic signatures between these two species sampled across the NE Atlantic. We specifically test whether differences in genetic diversity are related to differences in population size of the two species and whether the genetic signatures differ, as would be expected if neritic species are more prone to bottlenecks than oceanic taxa.

\section{Materials and methods}

Sampling and molecular analysis

Individuals of $S$. elegans and S. setosa were collected from the NE Atlantic during two research expeditions on the Research Vessel 'Pelagia' of the Royal Netherlands Institute for Sea Research (NIOZ) in August- 
Fig. 1 a Distribution of Sagitta elegans and $S$. setosa shown by different hatching patterns (based on maps in Alvariño 1965; Pierrot-Bults and Nair 1991; Peijnenburg et al. 2004). b Sampling localities of S. elegans and $S$. setosa from the NorthEast Atlantic (see alsoTable 1). Sample abbreviations used in a previous study by Peijnenburg et al. (2004) were N1=99skag1, $\mathrm{N} 3=99 \mathrm{gb} 1, \mathrm{~N} 9=99 \mathrm{sb} 3$, $\mathrm{N} 10=00 \mathrm{at} 11$, and N11 $=00$ celt 1

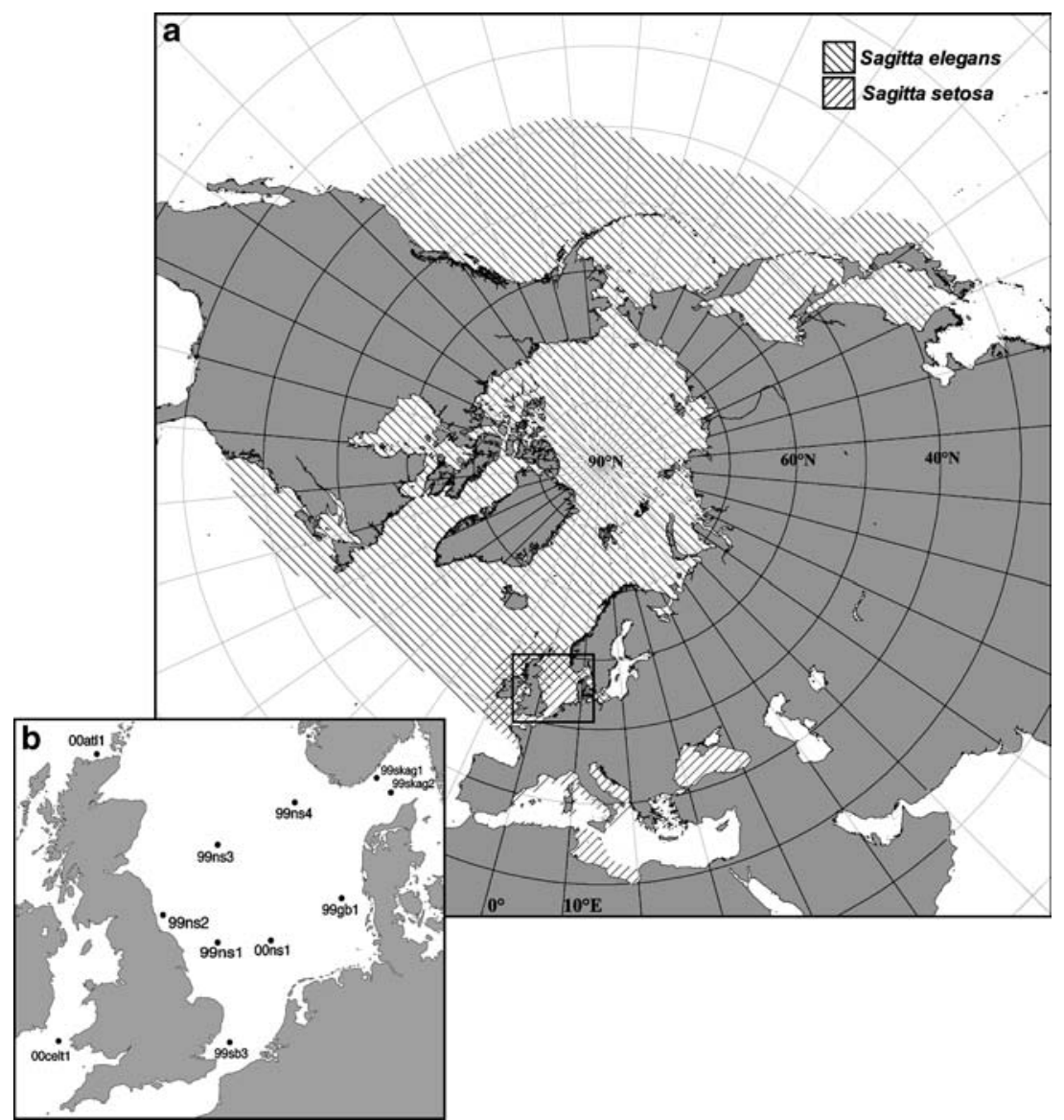

September 1999 (Cruise 64PE144) and SeptemberOctober 2000 (Cruise 64PE169, Table 1). Samples from 11 locations were selected for analyses, eight included $S$. elegans and five included S. setosa (Fig. 1b, Table 1). Vertical hauls were taken from close to the bottom (except for station '99skag1' that was $450 \mathrm{~m}$ deep) to the surface using a ring net of $1 \mathrm{~m}$ in diameter and a $500 \mu \mathrm{m}$ mesh size. Approximate relative abundances per haul are indicated in Table 1. These results are congruent with earlier reports that although both species co-occur in the NE Atlantic, $S$. elegans can be regarded as a species characteristic of the inflow of oceanic water and $S$. setosa as characteristic of coastal waters (Russell 1939; Bainbridge 1963). All live chaetognaths were examined under a binocular microscope aboard ship. Only mature individuals in good condition that were clearly identified to species, and without visible gut contents or parasites, were individually stored in

Table 1 Sagitta elegans and S. setosa sampling information, with sample abbreviations and regions (see also Fig. 1b)

\begin{tabular}{|c|c|c|c|c|c|c|c|}
\hline Station label & Region & $\begin{array}{l}\text { Depth } \\
\text { of haul }\end{array}$ & $\begin{array}{l}\text { Date of } \\
\text { collection }\end{array}$ & $\begin{array}{l}\text { S. elegans } \\
\text { abundance }\end{array}$ & $\begin{array}{l}S . \text { setosa } \\
\text { abundance }\end{array}$ & $\begin{array}{l}S . \text { elegans } \\
\text { analysed }(n)\end{array}$ & $\begin{array}{l}S . \text { setosa } \\
\text { analysed (n) }\end{array}$ \\
\hline 99ns1 & Central North Sea & 57 & 31.08 .99 & ++ & - & 4 & \\
\hline $99 \mathrm{~ns} 3$ & Central North Sea & 92 & 02.09 .99 & +++ & - & 5 & \\
\hline 99ns4 & Central North Sea & 80 & 04.09 .99 & ++ & + & 4 & \\
\hline 00ns1 & Central North Sea & 45 & 18.10 .00 & ++ & + & 5 & \\
\hline 99skag2 & Skagerrak & 100 & 05.09 .99 & +++ & ++ & 5 & \\
\hline $99 \mathrm{gbl}$ & German Bight & 29 & 08.09 .99 & - & +++ & & 8 \\
\hline $99 \mathrm{sb3}$ & Southern Bight & 44 & 15.09 .99 & - & +++ & & 6 \\
\hline Total & & & & & & 37 & 32 \\
\hline
\end{tabular}

Approximate abundance per haul ( - absent, + present $(<20$ individuals $),++$ abundant $(20-100$ individuals $),+++$ highly abundant ( $>100$ individuals)

$n$ the number of sequenced individuals for the Cytochrome Oxidase II fragment 
$\sim 300 \mu \mathrm{l}$ BLB buffer (250 mM EDTA, 5\% SDS, $50 \mathrm{mM}$ Tris-HCl pH 8.0; Holland 1993). Molecular protocols are described in Peijnenburg et al. (2004). Thirty-seven sequences of the mitochondrial Cytochrome Oxidase II (COII) region of $S$. elegans were added to a previous dataset of 32 sequences of $S$. setosa from the NE Atlantic (Peijnenburg et al. 2004, Table 1).

\section{Data analysis}

A $504 \mathrm{bp}$ fragment was unambiguously aligned for all individuals of $S$. elegans and S. setosa (69 sequences in total) in DAMBE (Xia and Xie 2001). DNA sequences were translated into amino acids using the invertebrate mitochondrial code to verify that these were protein coding genes, and not nuclear copies of mitochondrial DNA (Bensasson et al., 2001). We encountered two stop-codons and some gaps in S. elegans sequences, so we double-checked seven individuals by direct sequencing PCR products on an ABI 3100 Genetic Analyser (Applied Biosystems). We confirmed that the two substitutions resulting in stop-codons and all gaps were $\mathrm{PCR} /$ cloning artefacts, and estimated a PCR/cloning error rate of 0.004 . For analyses, we used only sequences from a single clone for each individual and treated all gaps as missing data.

Because of high sequence variability, we examined the extent of mutational saturation (multiple substitutions at single nucleotide positions) in DAMBE by plotting the total number of transitions and transversions against Jukes-Cantor (1969) genetic distances for every pairwise sequence comparison and for all three codon positions. Sequence comparisons within S. setosa were not saturated, and slight saturation within S. elegans comparisons was observed for transitions at third codon positions only. Interspecific comparisons were saturated at all three codon positions.

Evolutionary relationships among all haplotypes were examined using a distance matrix approach in PAUP* (Swofford 1998). Uncorrected P-distances and corrected Maximum Likelihood distances (using the General Time Reversible Model (Rodríguez et al. 1990) with gammadistributed rates with shape parameter $\alpha=0.6647$, as estimated in Modeltest, Posada and Crandall 1998) were calculated for within and between species comparisons, respectively. The neighbour-joining (NJ) algorithm (Saitou and Nei 1987) was used to construct unrooted phylograms from distance matrices and the robustness of nodes was assessed with 1,000 NJ-bootstrap replicates.

We tested for population subdivision between different regions in the NE Atlantic (see Table 1) and between different years (1999 and 2000) for each species, using analyses of molecular variance (AMOVA, Excoffier et al. 1992) as implemented in Arlequin (Schneider et al. 2000). The null hypothesis of genetic homogeneity among samples was tested using $\phi$-statistics (using uncorrected P-distances) and significance was assessed using 10,000 permutations.
To investigate levels of genetic diversity and the genetic signatures of $S$. elegans and $S$. setosa populations from the NE Atlantic, all sequences from different areas were pooled. Using DnaSP version 4.0 (Rozas et al. 2003), we calculated different estimators of genetic diversity, namely haplotype diversity (H, Nei 1987), nucleotide diversity ( $\pi$, Nei 1987), and the average number of nucleotide differences between two sequences ( $k$, Tajima 1983). Additionally, the number of segregating sites (S), the number of mutations $(\eta)$, and Watterson's theta $\left(\theta_{\mathrm{w}}\right.$, based on S, Watterson 1975) were computed.

Estimates of genetic diversity were used to calculate effective population size assuming a neutral model of evolution (Kimura 1983). Under such a model, both $\pi$ and $\theta_{\mathrm{w}}$ are estimates of the population mutation rate; $\theta$ $=2 N_{\mathrm{e}} \mu$ (in the case of a mitochondrial gene in a diploid organism, where $N_{\mathrm{e}}$ is the female effective population size (the number of breeding females in an idealised population, Nei 1987), and $\mu$ the mutation rate per generation). Hence, effective population size can be estimated if the mutation rate per generation is known. Note that in our case of hermaphroditic species, effective female population size is approximately equal to effective total population size when variance in reproductive success of males and females is similar. We used the conventional mutation rate of $2 \%$ divergence per million years for animal mitochondrial DNA (Avise 2000) and assumed a generation time of one year for both species (see Introduction).

We wished to compare our estimates of effective population size of $S$. elegans and S. setosa (based on genetic data) to estimated actual total population sizes. However, to our knowledge such estimations are unavailable for $S$. elegans and $S$. setosa. To roughly generate estimates we multiplied published data on average densities by our own estimates of the surface area and volume of known distributions. In the case of $S$. elegans, this included all marine habitats north of latitude $40^{\circ} \mathrm{N}$, comprising the northern parts of the Atlantic and Pacific oceans and Arctic and Subarctic regions, to a maximum depth of $150 \mathrm{~m}$ (Fig. 1a). In the case of $S$. setosa, only the distribution area of the NE Atlantic population was considered because it is now isolated from populations in the Mediterranean and Black Sea (Peijnenburg et al. 2004). Hence, this distribution comprised all neritic marine habitats between latitudes $45^{\circ} \mathrm{N}$ and $61^{\circ} 30^{\prime} \mathrm{N}$, and longitudes $12^{\circ} \mathrm{W}$ and $15^{\circ} \mathrm{E}$, roughly ranging from the western Baltic to the continental seas of the NE Atlantic (Fig. 1a). Volumes were adjusted for varying water depths according to a grid of $0.5 \times 0.5$ degrees $(\mathrm{H}$. van Aken, personal communication).

Demographic history of the two species was examined using mismatch distributions. For each species, we also computed two theoretical distributions using DnaSP, the first one as expected for an equilibrium population of constant population size, based on $\theta_{\mathrm{w}}$ as estimated from the data, and the second one as expected 
under a sudden expansion model (Rogers and Harpending 1992). This model considers a population that was formerly at equilibrium, but $\tau$ generations ago suddenly expanded (assuming $\theta_{1}$ (after the expansion) to be infinite according to recommendations in DnaSP). To test whether one model fitted the observed data better than the other model, we calculated square deviations (SD) between frequencies of observed pairwise differences and their expectations under the two different models. We used a paired $t$-test to test for differences in SDs. If significant, we assumed that the model with the smaller sum of all SDs (SSD) best explained our data.

To test for neutrality we computed the commonly used Tajima's $D$ statistic (Tajima 1989a) as well as the $R_{2}$ statistic (Ramos-Onsins and Rozas 2002), which use information from mutation frequencies. We chose the $R_{2}$ test because it was found to be the most powerful to reject neutrality in the case of population growth (Ramos-Onsins and Rozas 2002) and was suitable for our data. Using DnaSP, test statistics for each species were compared to their empirical distributions expected under the neutral model as generated by 10,000 coalescent simulations based on S. Additionally, the use of the same protein coding gene in two related species allowed us to specifically test for selection using a McDonaldKreitman test (McDonald and Kreitman 1991). This test is based on a prediction from neutral theory that the ratio of replacement (non-synonymous) to silent (synonymous) fixed differences observed between species, should equal the ratio of replacement to silent polymorphisms within species. For instance, a significant excess of replacement fixations indicates positive divergent selection.

\section{Results}

\section{General sequence characteristics}

All 69 sequenced individuals of S. elegans and S. setosa represented unique haplotypes resulting in maximum haplotypic diversity. Nevertheless, we are confident that our sequences represent mitochondrial COII coding sequences, for the following three reasons: (1) we found a close match with the COII gene of the recently sequenced entire mitochondrial genome of the first representative of the phylum Chaetognatha, Paraspadella gotoi, by BLASTP searching Genbank (Accession Number YP054597, Helfenbein et al. 2004), (2) we did not encounter any double peaks, stopcodons, or gaps in direct sequences of the same fragment, and (3) restriction digests of PCR products did not show multiple banding patterns (data not shown). DNA sequences are deposited in Genbank under Accession Numbers AY585585-AY585616 ( $S$. setosa from the NE Atlantic), AY585563, AY585564, and AY942657-AY942691 ( $S$. elegans).

Most mutations were at third codon positions in both species $(77.26 \%$ and $67.28 \%$ for S. elegans and S. setosa, respectively), but the relative proportions of transitions and transversions differed between the two species $(57.52 \%$ and $91.36 \%$ transitions at third codon positions for S. elegans and S. setosa, respectively), reflecting saturation at third codon transitions observed for $S$. elegans only (see Material and Methods). Translation into amino acid sequences revealed that replacement mutations were common. From a total of 167 aligned amino acid positions, 17 were polymorphic in both species, 44 were polymorphic in $S$. elegans only, 17 in $S$. setosa only, 71 were fixed and shared between the two species, and 18 were fixed but different between the two species. These results suggest that similar regions of the COII fragment were conserved between the species, but sequences of $S$. elegans were much more variable compared to $S$. setosa, both at the nucleotide as well as the protein level.

\section{Population structure}

Uncorrected pairwise distances between haplotypes within S. elegans were larger than for $S$. setosa, ranging from $0.99 \%$ to $12.95 \%$ (average \pm standard deviation, $6.30 \pm 2.74 \%$ ) compared to a range of $0.20-5.56 \%$ $(2.08 \pm 0.95 \%)$ for $S$. setosa. The average maximumlikelihood-corrected divergence between the two species was $77.70 \pm 3.45 \%$ (range $68.18-89.68 \%$ ). Reconstructions of evolutionary relationships amongst haplotypes revealed no within-species spatial or temporal structuring of samples (Fig. 2). Similarly, AMOVA analyses revealed no significant within-species structuring $\left(\phi_{\mathrm{st}^{-}}\right.$ values ranged from -0.02 to 0.004 between regions or between years for both species, all comparisons $P>0.26$ ). The unrooted NJ tree (Fig. 2) showed a starlike structure for $S$. setosa haplotypes (with the exception of a single deeper lineage from the German Bight, population sample ' $99 \mathrm{gbl}$ '). By contrast, the phylogeny of $S$. elegans haplotypes consisted of several well-supported subclades, indicating a deeper genealogical structure (Fig. 2).

\section{Mitochondrial diversity and population size}

Since we found no evidence of genetic differentiation in either species, all population samples within species could be grouped to estimate effective population sizes and conduct tests of selective neutrality and demographic history. The number of observed segregating sites (S) of $S$. elegans sequences was approximately twice that of $S$. setosa sequences (192 and 94, respectively), whereas nucleotide diversity $(\pi)$ for $S$. elegans was about three times that for $S$. setosa $(0.0612$ and 0.0208 , respectively, Table 2). Likewise, estimates of $\theta_{\mathrm{w}}$ suggested a $\sim 2.6$ times deeper genealogical structure in $S$. elegans compared to $S$. setosa (Table 2). Converting estimates of $\pi$ and $\theta_{\mathrm{w}}$ into effective population sizes of the two species resulted in a $\sim 2.6$ to 3 times larger 
Fig. 2 Unrooted NeighbourJoining phylogram of all Sagitta elegans (shown on the left) and $S$. setosa (shown on the right) mitochondrial Cytochrome Oxidase II haplotypes (based on P-distances). Nodes with more than $80 \%$ bootstrap support are indicated with black dots. Numbers in brackets denote the number of individuals per population sample found for a particular clade, if more than one. Average maximum likelihood divergence between $S$. elegans and $S$. setosa was $77.70 \pm 3.45 \%$ (standard deviation)

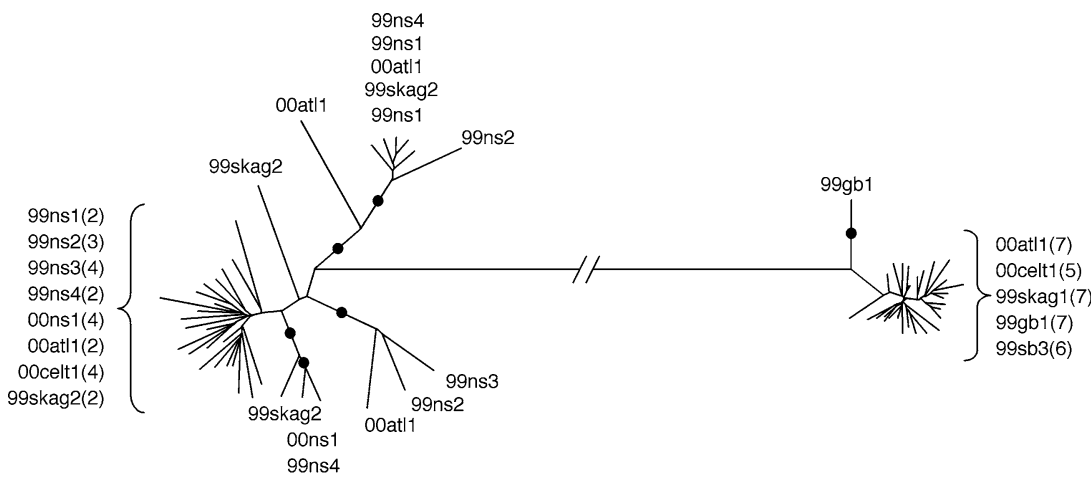

Sagitta elegans

Sagitta setosa estimate for $S$. elegans than for $S$. setosa, assuming similar mutation rates for both species. Applying a standard mutation rate of $10^{-8}$ mutations per generation, we estimated effective population sizes of $4.7-$ $6.1 \times 10^{6}$ for S. elegans, and $2.1-2.3 \times 10^{6}$ for S. setosa (Table 2).

Estimates of effective population sizes were substantially smaller than our estimates of total population sizes based on the distribution and average abundances of the two species. Published estimates of the average density of S. elegans are 460 and 560 individuals per $\mathrm{m}^{2}$ in the Celtic Sea (Conway and Williams 1986) and Arctic Ocean (Choe and Deibel 2000), respectively, and 1.4 and 6.8 individuals per $\mathrm{m}^{3}$ in the SW North Sea (Wimpenny 1936) and North Pacific (Fager and McGowan 1963), respectively. Assuming an average abundance for $S$. elegans of $500 / \mathrm{m}^{2}$ or $5 / \mathrm{m}^{3}$ over its entire range, and an estimated distribution of $4.2 \times 10^{13} \mathrm{~m}^{2}$ or $5.6 \times 10^{15} \mathrm{~m}^{3}$, we obtained an overall population size of $2.1 \times 10^{16}$ (based on area) or $2.8 \times 10^{16}$ (based on volume, Table 2). Compared to S. elegans, observed densities of $S$. setosa in the NE Atlantic were larger, $\sim 1,100 / \mathrm{m}^{2}$ (Øresland 1983) and $\sim 55 / \mathrm{m}^{3}$ (Wimpenny 1936). Using an overall average density of $1,000 /$ $\mathrm{m}^{2}$ and $50 / \mathrm{m}^{3}$ and an estimated distribution in the NE
Atlantic of $1.0 \times 10^{12} \mathrm{~m}^{2}$ or $6.6 \times 10^{13} \mathrm{~m}^{3}$, the overall population size of $S$. setosa was $1.0 \times 10^{15}$ (based on area) or $3.3 \times 10^{15}$ (based on volume, Table 2). Thus, both surface area and volume estimates of census population sizes were similar for both species, and $S$. elegans had an approximately 8-20 times larger census population size than $S$. setosa. Compared with effective population size estimates, our calculations of census population sizes were much larger, by a factor of 3.4 $6.0 \times 10^{9}$ for $S$. elegans and $4.4-15.7 \times 10^{8}$ for $S$. setosa.

\section{Demographic history and neutrality}

Mismatch distributions differed strikingly between the two species (Fig. 3). The distribution of S. elegans was multi-modal with a mean of 29.87 pairwise differences and a distribution ranging from 5 to 62 differences. This is among the patterns that might be expected in a stable size population (Slatkin and Hudson 1991; Rogers and Harpending 1992). Conversely, the mismatch distribution of $S$. setosa was less broad (between one and 28 pairwise differences and a mean of 10.41 differences) and had a uni-modal shape with the main peak at eight pairwise differences reflecting the star phylogeny found
Table 2 Genetic diversity estimators and estimated census and effective population sizes for Sagitta elegans and S. setosa

Estimates of average densities of the two chaetognath species are based on results from $\mathrm{Wi}$ mpenny (1936), Fager and McGowan (1963), Øresland (1983), Conway and Williams (1986), and Choe and Deibel (2000, see Results)

\begin{tabular}{|c|c|c|}
\hline & S. elegans & S. setosa \\
\hline \multicolumn{3}{|l|}{ Diversity estimators } \\
\hline Number of haplotypes & 37 & 32 \\
\hline Number of segregating sites (S) & 192 & 94 \\
\hline Number of mutations $(\eta)$ & 251 & 96 \\
\hline Average number of nucleotide differences $(k)$ & 29.87 & 10.41 \\
\hline Nucleotide diversity $(\pi)$ & 0.0612 & 0.0208 \\
\hline Theta per site from $\mathrm{S}\left(\theta_{\mathrm{w}}\right.$, Watterson 1975$)$ & 0.0943 & 0.0467 \\
\hline \multicolumn{3}{|l|}{ Estimation of population size } \\
\hline Average density per $\mathrm{m}^{2}$ & 500 & 1,000 \\
\hline Average density per $\mathrm{m}^{3}$ & 5 & 50 \\
\hline Distribution (area) in $\mathrm{m}^{2}$ & $4.2 \times 10^{13}$ & $1.0 \times 10^{12}$ \\
\hline Distribution (volume) in $\mathrm{m}^{3}$ & $5.6 \times 10^{15}$ & $6.6 \times 10^{13}$ \\
\hline Census population size (based on area) & $2.1 \times 10^{16}$ & $1.0 \times 10^{15}$ \\
\hline Census population size (based on volume) & $2.8 \times 10^{16}$ & $3.3 \times 10^{15}$ \\
\hline Effective population size from $\pi$ & $6.1 \times 10^{6}$ & $2.1 \times 10^{6}$ \\
\hline Effective population size from $\theta_{\mathrm{w}}$ & $4.7 \times 10^{6}$ & $2.3 \times 10^{6}$ \\
\hline
\end{tabular}


for this species (Fig. 2). This pattern is suggestive of a bottleneck followed by a sudden population expansion (Slatkin and Hudson 1991; Rogers and Harpending 1992). An additional small peak was apparent at 24 differences, which resulted from the inclusion of a single representative of a deep clade (individual N3-3 in Peijnenburg et al. 2004). For S. elegans, no significant difference was found between the fit of the observed data to that expected under a stable population size model, or the sudden expansion model (paired $t$-test, $\mathrm{df}=58$, $P=0.98$ ), whereas for $S$. setosa, the fit of the two models was significantly different (paired $t$-test, $\mathrm{df}=28$, $P=0.002$ ). The lower SSD for the sudden expansion model indicated that this model provided the best fit to our data (Fig. 3). Based on this model, with parameters $\theta_{0}=3.51, \theta_{1}=$ infinite, and $\tau=6.9$, we calculated that an expansion of the NE Atlantic population of S. setosa started approximately 685,000 generations ago (using the formula $\tau=2 u t$, where $u$ is the mutation rate of the entire sequence and $t$ is the number of generations, Rogers and Harpending 1992).

The $R_{2}$ neutrality test resulted in a significant rejection of the neutral model for both species, with a lower $R_{2}$ value for $S$. setosa, which is typical of a recently expanded population $\left(S\right.$. elegans: $R_{2}=0.0583, P<0.01$; $S$. setosa: $\left.R_{2}=0.0400, P<0.001\right)$. The commonly used Tajima's $D$ test, however, did not reject neutrality for $S$. elegans, but did reject this for $S$. setosa ( $S$. elegans: $D=-1.315, P>0.10 ; S$. setosa: $D=-2.091, P<0.05)$. The McDonald-Kreitman test revealed a significantly higher ratio of replacement to silent fixed differences between species $(35: 38=0.921)$ compared to the ratio of replacement to silent polymorphisms within species $(54: 139=0.388)$, indicating positive selection of the COII gene during the evolution of these species (Fisher's exact test, $P=0.003$ ).

\section{Discussion}

Our study of mitochondrial COII sequences of two chaetognaths $S$. elegans and $S$. setosa from the NE Atlantic is one of the few studies that has examined genetic variation in zooplankton. High levels of genetic diversity combined with a lack of genetic structuring enabled us to contrast the two species' present genetic composition. The strength of this approach is that we compared the same gene for two systematically and
Fig. 3 Mismatch distributions of pairwise sequence differences for Sagitta elegans (top) and S. setosa (bottom). Expected distributions under a model of constant population size and under a sudden population expansion model are indicated as computed in DnaSP. Sum of squared deviations (SSD) between the observed data and the two theoretical models are shown on the right as well as the $P$ values of the paired $t$-test testing for a difference in fit between the two models and the observed data

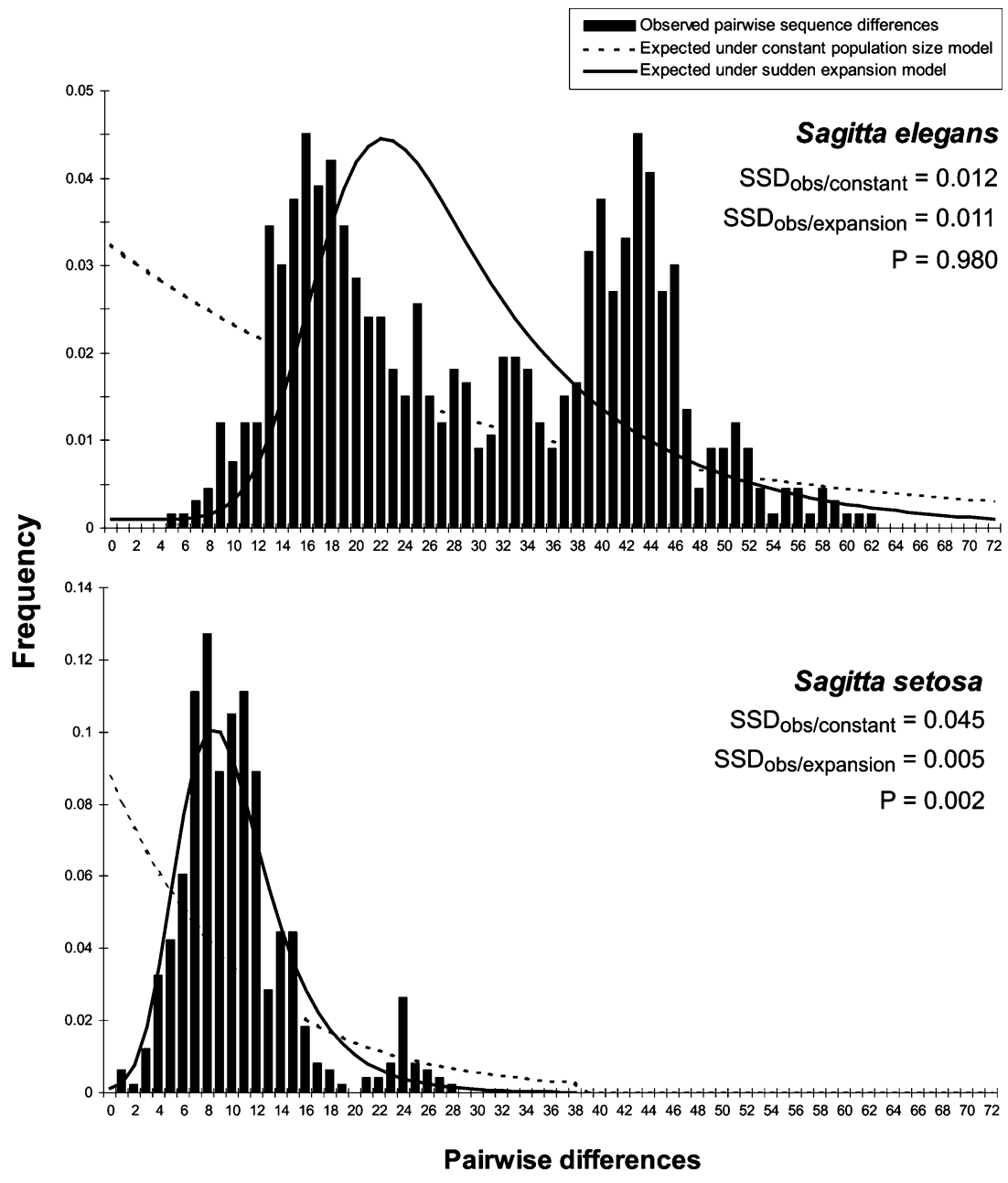


ecologically related species, which differed mainly in distributional ranges.

\section{Mitochondrial diversity}

Sagitta elegans and S. setosa both possessed very high levels of genetic diversity with unique haplotypes for every sequenced individual and nucleotide diversities $(\pi)$ of 0.061 and 0.021 , respectively. This is surprising because COII is generally considered a conserved proteincoding gene (e.g., Simon et al. 1994). Compared to other studies of mitochondrial diversity in zooplankton, our estimates of $\pi$ are among the highest ever reported. For example in pelagic crustaceans (copepods and euphausids) $\pi$ values ranged from 0.002 to 0.018 (Bucklin et al. 1997, 2000; Bucklin and Wiebe 1998; Zane et al. 2000; Papadopoulos et al. 2005). However, these studies are not strictly comparable because different mitochondrial genes were used, which may differ in mutation rate. High levels of genetic diversity are often explained by large population sizes (Nei 1987; Avise et al. 1989) and the enormous population sizes of zooplankton, which are among the largest in the animal kingdom (Bucklin and Wiebe 1998; Norris 2000) may explain the high levels of diversity that we found. A small fraction of the diversity may also be explained by PCR/cloning artefacts. For example, while assuming an error rate of 0.004 (see Materials and Methods) a maximum of $5 \%$ of the pairwise comparisons for $S$. setosa may have been between identical haplotypes, but none of the pairwise comparisons for $S$. elegans.

Based on $\pi$ and $k$, which are corrected for sample size, mitochondrial diversity was about three times higher for S. elegans than for S. setosa. Comparing our results with COII variability in different populations of S. setosa from Peijnenburg et al. (2004) indicated lower estimates of nucleotide diversity of the NE Atlantic population of $S$. setosa (0.021) compared to Mediterranean populations $(0.026$ and 0.027$)$ but higher estimates compared to the Black Sea population (0.015). Sagitta elegans displayed higher levels of nucleotide diversity (0.061) than any of the $S$. setosa populations. This finding is congruent with our estimates of a $\sim 8-20$ times larger census population size of $S$. elegans compared to S. setosa.

\section{Effective versus census population size}

We found a large discrepancy between effective population sizes and our estimates of total population sizes $\left(4.4 \times 10^{8}-6.0 \times 10^{9}-\right.$ fold smaller effective than census population sizes). Even though both estimates depend on several assumptions that are likely to be violated (see below) and should therefore be interpreted with caution, the difference is striking and unlikely to be an artefact of the method. For instance, the estimation of effective population size depends on the assumption that the standard $2 \%$ clock is correct for the evolution of chaetognath mtDNA. In addition, estimates of effective population size depend on estimates of $\theta$, which assume an idealised population and a neutral model of evolution. The fact that our estimates of effective population size based on $\theta_{\mathrm{w}}$ and $\pi$ differ (Table 2) suggests that one or more assumptions of the neutral model are invalid (see also next section). However, there exists no alternative for the neutral model to estimate effective population sizes. The estimation of census population size for the two species is also very approximate because of the scarcity of data on species abundances in different seasons and across their entire geographical ranges.

Nevertheless, a large discrepancy between effective and census population size has commonly been observed in marine species (Grant and Bowen 1998; Avise 2000). For zooplankton, large discrepancies were reported for Antarctic krill ( $\sim 10^{9}$-fold difference, Zane et al. 1998) and two North Atlantic copepods $\left(\sim 10^{10}\right.$-fold difference, Bucklin and Wiebe 1998). Explanations for these discrepancies, none of which are mutually exclusive, have included: (1) a large variance in reproductive success among individuals, (2) overlapping generations, (3) extinction and recolonisations of local subpopulations, (4) historical fluctuations in population size, and (5) selective sweeps. The first explanation is very likely for species with high fecundities such as chaetognaths, resulting in huge variances in progeny numbers among families with consequent lowering of effective population size (Hedgecock 1994; Avise et al. 1989). Overlapping generations may also be possible for S. elegans and $S$. setosa because it is known that both species can lay several batches of eggs and sometimes over prolonged periods (Dallot 1968; Jakobsen 1971). Even though we assumed a single generation per year for each species, the exact number of breeding cycles in different regions of the NE Atlantic is still a topic of discussion (Pearre 1991). The third explanation of local subpopulations (Slatkin 1985; Whitlock and Barton 1997, Avise 2000) may be applicable to zooplankton populations as they are often patchily distributed. However, we found no evidence of population structuring over evolutionary timescales for the two chaetognaths in the NE Atlantic, which renders this possibility less likely. The fourth and fifth explanations of historical fluctuations in population size and selective sweeps have been hypothesised for many northern temperate species that are affected by Pleistocene glaciations (e.g., Hewitt 1996) and it has been shown that they can have significant effects on the genetic composition of even highly abundant marine species (Avise et al. 1988; Grant and Bowen 1998; Bucklin and Wiebe 1998). However, the genetic signature of a population bottleneck followed by an expansion may be very similar to that of a selective sweep in a constant-sized population (Tajima 1989b; Donnelly and Tavaré 1995), making the two difficult to disentangle. Though results of different neutrality tests varied, the McDonald-Kreitman test, which was specifically designed to test for selection (McDonald and Kreitman 
1991; Brookfield and Sharp 1994; Skibinski 2000), indicated highly significant evidence for positive selection on the COII gene during the evolution of S. elegans and $S$. setosa. It has been suggested, however, that the significance may be inflated because sequences of the two species are saturated with respect to each other (see Whittam and Nei 1991). Thus, assumptions of the neutral model are violated for both species and may be explained by bottlenecks as well as directional selection.

\section{Demographic history}

The genetic signatures of $S$. elegans and $S$. setosa are strikingly different when depicted as phylograms (Fig. 2) and mismatch distributions (Fig. 3). Sagitta setosa had mtDNA haplotypes showing a star-like phylogeny and a uni-modal mismatch distribution, whereas $S$. elegans had a much deeper mtDNA phylogeny and a multimodal mismatch distribution. Although selection has probably played a significant role in determining the two species' present genetic composition, it is not a likely explanation for the difference in genetic signature between the two species because the two chaetognaths are biologically very similar. Assuming that selective effects have been the same during the evolutionary history of the two species, the deeper genealogical structure of $S$. elegans compared to $S$. setosa may be explained if: (1) $S$. elegans is a much older species than $S$. setosa, (2) genetically differentiated groups were sampled for $S$. elegans and not for $S$. setosa, and (3) S. elegans was less affected by bottlenecks compared to $S$. setosa. The first possibility of $S$. elegans being a much older species than $S$. setosa is unlikely because based on a molecular species phylogeny, Telford and Holland (1997) suggested a rapid, recent radiation of different groupings within the genus 'Sagitta', which included the grouping 'Parasagitta' to which both species belonged. The second possibility of genetically differentiated groups within $S$. elegans may be important in the light of three subspecies that have been described; one from the Arctic (S. elegans arctica Aurivillius, 1896), one from the Subarctic ( $S$. elegans elegans Verrill, 1873), and another from the Baltic (S. balthica Ritter-Zahony, 1911). However, most authors consider these as local forms representing only variability in size, which may be a phenotypically plastic response to the water temperature in which they develop (Fraser 1952; Alvariño 1965; Pierrot-Bults and Nair 1991). Moreover, all our samples were taken from areas where only the variant 'elegans' had been reported and we did not observe any apparent differences in the sizes of sampled individuals. It may be possible though, that $S$. elegans is genetically structured over broader geographical scales than we sampled, and that divergent lineages have colonised the NE Atlantic through occasional dispersal. One earlier study using allozymes to study the genetic structure of $S$. elegans from the waters off Japan suggested subtle differentiation between populations, but results were contradictory (Thuesen et al.
1993). A more broad-scale genetic survey of S. elegans populations is necessary to reveal whether the entire species can be regarded as panmictic or not. Our lack of evidence for genetic structuring of populations in the NE Atlantic, however, taken together with other studies of so-called 'high gene flow' species occurring above the shelf in this region (Borsa et al. 1997; Shaw et al. 1999; Hoarau et al. 2002, 2004) suggest that population structuring in the NE Atlantic of S. elegans is unlikely to be the case.

The evidence suggests that the difference in genetic signature of $S$. elegans and $S$. setosa is most likely due to a difference in demographic history. We found a clear genetic signature of a population bottleneck followed by a sudden expansion for $S$. setosa, but not for $S$. elegans. Reconstructions of seawater temperatures and current patterns in the North Atlantic during the last glacial maximum (18,000 years ago) based on foraminiferal and coccolithophorid assemblages, show that northern temperate conditions were compressed and shifted southwards compared to present conditions (McIntyre et al. 1976; Angel 1979). If we assume that distributional ranges of $S$. elegans and $S$. setosa were similar during warm periods (interglacials) of the Pleistocene compared to the present, then both species were severely affected during glacial periods, with drops in temperature exceeding $10^{\circ} \mathrm{C}$ (McIntyre et al. 1976) and drops in sea level of at least $85 \mathrm{~m}$ (CLIMAP 1976) resulting in a complete covering with pack ice of the NE Atlantic shelf. Our results support the hypothesis that a neritic species such as $S$. setosa, which presently occurs only above continental shelf areas, is more affected by bottlenecks resulting from repeated glaciations compared to a more oceanic species with a wider distribution pattern such as $S$. elegans. This is presumably because the distribution of $S$. setosa was not just severely compressed, but ultimately completely displaced. By contrast, even though populations of $S$. elegans were also severely compressed, they were not completely displaced, and may have been buffered against bottlenecks because populations were larger, continuous, and more extensive. We estimated from our mitochondrial data that a major demographic expansion of the NE Atlantic population of $S$. setosa started approximately 685,000 generations ago, during the mid-Pleistocene (assuming one generation per year). However, such estimates should be regarded as very approximate because they are based on a simple demographic model, there is a large variance associated with estimates of $\tau$ from a single locus, and estimates are highly reliant on the estimate of mutation rate and generation time of the organism.

In summary, our study of mitochondrial variation in two chaetognaths contributes to the existing literature of other superabundant and high gene flow species that long term evolutionary (effective) population sizes may be relatively small. The comparison of two species with different distribution patterns has shown that planktonic species may be differentially affected by geological events such as ice ages because of differences in ecolog- 
ical traits. Furthermore, our study adds to a growing body of literature, suggesting that mitochondrial markers should not be regarded as strictly neutrally evolving (e.g., reviewed in Ballard and Whitlock 2004).

Acknowledgements We thank all crew of the research vessel Pelagia, R. ter Hofstede, and J.-H Schotveld for their help in taking plankton samples and C. ten Hallers-Tjabes for inviting KP, and $\mathrm{H}$. van Aken for inviting KP and EH aboard their research cruises. $H$. van Aken is also thanked for his calculations of the areas and volumes of the distributions of the two chaetognaths. W. van Ginkel, P. Kuperus, and B. Voetdijk are acknowledged for laboratory assistance and $\mathbf{J}$. van Arkel for his help with figures. We thank G. Lecaillon, P. Meirmans, A. Pierrot-Bults, and A. Southward for discussion. Comments of J. Breeuwer, M. Egas, M. Genner, P. Luttikhuizen, and S. Menken improved the manuscript. This research was funded by the Netherlands Organisation for Scientific Research (NWO) as part of the priority program 'Sustainable use and conservation of marine living resources' project number 885.100.02. Research was carried out in accordance with all laws and regulations of the Netherlands.

\section{References}

Alvariño A (1965) Chaetognaths. Oceanogr Mar Biol Ann Rev 3:115-194

Andersen BG, Borns HW Jr (1994) The ice age world. Scandinavian Univ Press, Oslo

Angel MV (1979) Zoogeography of the Atlantic Ocean. In: Van der Spoel S, Pierrot-Bults AC (eds) Zoogeography and diversity of plankton. Bunge, Utrecht, pp 168-190

Angel MV (1993) Biodiversity of the pelagic ocean. Cons Biol $7: 760-772$

Arnaud S, Bonhomme F, Borsa P (1999) Mitochondrial DNA analysis of the genetic relationships among populations of scad mackerel (Decapterus macarellus,D. macrosoma, and D. russelli) in South-East Asia. Mar Biol 135:699-707

Avise JC, Ball RM, Arnold J (1988) Current versus historical population sizes in vertebrate species with high gene flow: a comparison based on mitochondrial DNA lineages and inbreeding theory for neutral mutations. Molec Biol Evol $5: 331-344$

Avise JC, Bowen BW, Lamb T (1989) DNA fingerprints from hypervariable mitochondrial genotypes. Molec Biol Evol 6:258269

Avise JC (2000) Phylogeography. The history and formation of species. Harvard Univ Press, Cambridge

Bainbridge V (1963) Continuous plankton records: Contribution towards a plankton atlas of the North Atlantic and the North Sea. VII: Chaetognatha. Hull Bull Mar Ecol 6:40-51

Ballard JWO, Whitlock MC (2004) The incomplete natural history of mitochondria. Molec Ecol 13:729-744

Bensasson D, Zhang DX, Hartl DL, Hewitt GM (2001) Mitochondrial pseudogenes: evolution's misplaces witnesses. Trends Ecol Evol 16:314-321

Bieri R (1991) Systematics of the Chaetognatha. In: Bone Q, Kapp $\mathrm{H}$, Pierrot-Bults AC (eds) The biology of Chaetognaths. Oxford press, Oxford, pp 122-136

Bone Q, Kapp H, Pierrot-Bults AC (1991) Introduction and relationships of the group. In: Bone Q, Kapp H, Pierrot-Bults AC (eds) The biology of Chaetognaths. Oxford press, Oxford, pp 14

Borsa P, Blanquer A, Berrebi P (1997) Genetic structure of the flounders Platichthys flesus and P. stellatus at different geographic scales. Mar Biol 129:233-246

Brookfield JFY, Sharp PM (1994) Neutralism and selectionism face up to DNA data. Trends Genet 10:109-111
Bucklin A, Smolenack SB, Bentley AM, Wiebe PH (1997) Gene flow patterns of the euphausiid, Meganyctiphanes norvegica, in the NW Atlantic based on mtDNA sequences for cytochrome $b$ and cytochrome oxidase I. J Plankt Res 19:1763-1781

Bucklin A, Wiebe PH (1998) Low mitochondrial diversity and small effective population sizes of the copepods Calanus finmarchicus and Nannocalanus minor: possible impact of climatic variation during recent glaciation. J Hered 89:383-392

Bucklin A, Kaartvedt S, Guarnieri M, Goswami U (2000). Population genetics of drifting (Calanus spp.) and resident (Acartia clausi) plankton in Norwegian fjords. J Plankt Res 22:1237-1251

Choe N, Deibel D (2000) Seasonal vertical distribution and population dynamics of the chaetognath Parasagitta elegans in the water column and hyperbenthic zone of Conception Bay, Newfoundland. Mar Biol 137:847-856

CLIMAP Project members (1976) The surface of the ice-age earth. Science 191:1131-1137

Conway DVP, Williams R (1986) Seasonal population structure, vertical distribution and migration of the chaetognath Sagitta elegans in the Celtic Sea. Mar Biol 93:377-387

Dallot S (1968) Observations préliminaires sur la reproduction en élevage du Chaetognathe planctonique Sagitta setosa Müller. Rapp Comm int Mer Médit 19:521-523

Donnelly P, Tavaré S (1995) Coalescents and genealogical structure under neutrality. Annu Rev Gen 29:401-421

Dudgeon CL, Gust N, Blair D (2000) No apparent genetic basis to demographic differences in scarid fishes across continental shelf of the Great Barrier Reef. Mar Biol 137:1059-1066

Excoffier L, Smouse PE, Quattro JM (1992) Analysis of molecular variance inferred from metric distances among DNA haplotypes: application to human mitochondrial DNA restriction data. Genetics 131:497-491

Fager EW and McGowan JA (1963) Zooplankton species groups in the North Pacific. Science 140:453-460

Fauvelot C, Bernardi G, Planes S (2003) Reductions in the mitochondrial DNA diversity of coral reef fish provide evidence of population bottlenecks resulting from Holocene sea-level change. Evolution 57:1571-1583

Feigenbaum D (1991) Food and feeding behaviour. In: Bone Q, Kapp H, Pierrot-Bults AC (eds) The biology of Chaetognaths. Oxford press, Oxford, pp 45-54

Fraser JH (1952) The Chaetognatha and other zooplankton of the Scottish area and their value as biological indicators of hydrographic conditions. Mar Res Scotl 2:5-52

Grant WS, Bowen BW (1998) Shallow population histories in deep evolutionary lineages of marine fishes: Insights from sardines and anchovies and lessons for conservation. J Hered 89:415-426

Hedgecock D (1994) Does variance in reproductive success limit effective population sizes of marine organisms? In: Beaumont A (ed) Genetics and evolution of aquatic organisms. Chapman and Hall, London, pp 122-134

Helfenbein KG, Fourcade HM, Vanjani RG, Boore JL (2004) The mitochondrial genome of Paraspadella gotoi is highly reduced and reveals that chaetognaths are a sister group to protostomes. Proc Natl Acad USA 101:10639-10643

Hewitt GM (1996) Some genetic consequences of ice ages, and their role in divergence and speciation. Biol J Linn Soc 58:247-276

Hoarau G, Rijnsdorp AD, Van der Veer HW, Stam WT, Olsen JL (2002) Population structure of plaice (Pleuronectes platessa L.) in northern Europe: microsatellites revealed large-scale spatial and temporal homogeneity. Molec Ecol 11:1165-1176

Hoarau G, Piquet AMT, van der Veer HW, Rijnsdorp AD, Stam W, Olsen JL (2004) Population structure of plaice (Pleuronectes platessa L.) in northern Europe: a comparison of resolving power between microsatellites and mitochondrial DNA data. J Sea Res 51:183-190

Holland PWH (1993) Cloning genes using the polymerase chain reaction. In: Stern CD, Holland PWH (eds) Developmental biology: a practical approach. Oxford University Press, Oxford, pp 243-255 
Jakobsen T (1971) On the biology of Sagitta elegans Verrill and Sagitta setosa J. Müller in Inner Oslofjord. Norw J Zool 19:201-225

Jukes TH, Cantor CR (1969) Evolution of protein molecules. In: Munro HM (ed) Mammalian protein metabolism. Academic, New York, pp 21-132

Kimura M (1983) The neutral theory of molecular evolution. Cambridge University Press, London

McDonald JH, Kreitman M (1991) Adaptive protein evolution at the Adh locus in Drosophila. Nature 351:652-654

McIntyre A, Kipp NG, Bé AWH, Cowley T, Kellogg T, Gardner JV, Prell W, Ruddiman WF (1976) Glacial North Atlantic 18,000 years ago: a CLIMAP reconstruction. In: Cline RM, Hayes JD (eds) Geolog Soc Am Mem 145, pp 43-74

Meek A (1928) On Sagitta elegans and Sagitta setosa from the Northumbrian Plankton, with a note on a trematode parasite. Proc Zool Soc Lond 743-776

Nei M (1987) Molecular evolutionary genetics. Columbia University Press, New York

Norris RD (2000) Pelagic species diversity, biogeography, and evolution. Paleobiology 26:236-258

Oresland V (1983) Abundance, breeding and temporal size distribution of the chaetognath Sagita setosa in the Kattegat. J Plankt Res 5:425-439

Øresland V (1986) Temporal distribution of size and maturity stages of the chaetognath Sagitta setosa in the western English Channel. Mar Ecol Prog Ser 29:55-60

Oresland V (1987) Feeding of the chaetognaths Sagitta elegans and $S$. setosa at different seasons in Gullmarsfjorden, Sweden. Mar Ecol Prog Ser 39:69-79

Papadopoulos LP, Peijnenburg KTCA, Luttikhuizen PC (2005) Marine Biology. Phylogeography of the calanoid copepods Calanus helgolandicus and $C$. euxinus suggests Pleistocene divergences between Atlantic, Mediterranean, and Black Sea populations. DOI 10.1007/s00227-005-0038-x

Pearre S (1991) Growth and reproduction. In: Bone Q, Kapp H, Pierrot-Bults AC (eds) The biology of Chaetognaths. Oxford press, Oxford, pp 61-75

Peijnenburg KTCA, Breeuwer JAJ, Pierrot-Bults AC, Menken SBJ (2004) Phylogeography of the planktonic chaetognath Sagitta setosa reveals isolation in European seas. Evolution 58:14721487

Pierrot-Bults AC, Nair VR (1991) Distribution patterns in Chaetognatha. In: Bone Q, Kapp H, Pierrot-Bults AC (eds) The biology of Chaetognaths. Oxford press, Oxford, pp 86-116

Pierrot-Bults AC, van der Spoel S (2003). Macrozooplankton diversity: how much do we really know? Zool Verh Leiden 345:297-312

Posada D, Crandall KA (1998) Modeltest: testing the model of DNA substitution. Bioinformatics 14:917-818

Ramos-Onsins S, Rozas J (2002) Statistical properties of new neutrality tests against population growth. Molec Biol Evol 19:2092-2100

Rodríguez F, Oliver JF, Marín A, Medina JR (1990) The general stochastic model of nucleotide substitution. J Theor Biol 142:485-501

Rogers AR, Harpending H (1992) Population growth makes waves in the distribution of pairwise genetic differences. Molec Biol Evol 9:552-569

Rozas J, Sánchez-Delbarrio JC, Messeguer X, Rozas R (2003) DnaSP, DNA polymorphism analyses by the coalescent and other methods. Bioinformatics 19:2496-2497

Russell FS (1932a) On the biology of Sagitta. The breeding and growth of Sagittaelegans Verrill in the Plymouth area, 1930-31. J Mar Biol Assoc UK 18:131-146

Russell FS (1932b) On the Biology of Sagitta. II. The breeding and growth of Sagittasetosa J. Müller in the Plymouth area, 1930-
31, with a comparison with that of S. elegans Verrill. J Mar Biol Assoc UK 18:147-160

Russell FS (1939) Hydrographical and biological conditions in the North Sea as indicated by plankton organisms. J Cons perm Int Explor Mer 14:171-192

Saitou N, Nei M (1987) The neighbor-joining method: a new method for reconstructing phylogenetic trees. Molec Biol Evol 4:406-425

Schneider S, Roessli D, Excoffier L (2000) Arlequin ver. 2.000: a software for population genetics data analysis. Genetics and Biometry Laboratory, University of Geneva, Geneva

Shaw PW, Pierce GJ, Boyle PR (1999) Subtle population structuring within a highly vagile marine invertebrate, the veined squid Loligo forbesi, demonstrated with microsatellite DNA markers. Molec Ecol 8:407-417

Simon C, Frati F, Beckenbach A, Crespi B, Liu H, Flook P (1994) Evolution, weighting, and phylogenetic utility of mitochondrial gene sequences and a compilation of conserved PCR primers. Ann Entomol Soc Am 87:651-701

Skibinski DOF (2000) DNA tests of neutral theory: applications in marine genetics. Hydrobiologia 420:137-152

Slatkin M (1985) Gene flow in natural populations. Annu Rev Ecol Syst 16:393-430

Slatkin M, Hudson RR (1991) Pairwise comparisons of mitochondrial DNA sequences in stable and exponentially growing populations. Genetics 129:555-562

Swofford DL (1998) PAUP*, phylogenetic analysis using parsimony (*and other methods), version 4. Sinauer Assoc, Sunderland

Tajima F (1983) Evolutionary relationship of DNA sequences in finite populations. Genetics 105:437-460

Tajima F (1989a) Statistical method for testing the neutral mutation hypothesis by DNA polymorphism. Genetics 123:585-595

Tajima $F(1989 b)$ The effect of change in population size on DNA polymorphism. Genetics 123:597-601

Telford MJ, Holland PWH (1997) Evolution of 28S ribosomal DNA in chaetognaths: duplicate genes and molecular phylogeny. J Molec Evol 44:135-144

Thuesen EVK, Numachi K, Nemoto T (1993) Genetic variation in the planktonic chaetognaths Parasagitta elegans and Eukrohnia hamata. Mar Ecol Prog Ser 101:243-251

Tokioka T (1979) Neritic and oceanic plankton. In: Van der Spoel S, Pierrot-Bults AC (eds) Zoogeography and diversity of plankton. Bunge, Utrecht, pp 126-143

Van der Spoel S, Heyman RP (1983) A comparative atlas of zooplankton. Biological patterns in the oceans. Bunge, Utrecht

Watterson GA (1975) On the number of segregating sites in genetical models without recombination. Theor Popul Biol 7:256-276

Whitlock MC, Barton NH (1997) The effective size of a subdivided population. Genetics 146:427-441

Whittam TS, Nei M (1991) Neutral mutation hypothesis test. Nature 354:115-116

Wimpenny RS (1936) The distribution, breeding and feeding of some important plankton organisms of the South-West North Sea in 1934. I. Calanus finmarchius (Gunn), Sagitta setosa (J Müller) and S. elegans (Verrill). Fish invest Lond 15:1-53

Xia X, Xie Z (2001) DAMBE: data analysis in molecular biology and evolution. J Hered 92:371-373

Zane L, Ostellari L, Maccatrozzo L, Bargelloni L, Battaglia B Patarnello T (1998) Molecular evidence for genetic subdivision of Antarctic krill (Euphausia superba Dana) populations. Proc Roy Soc Lond Ser B 265:2387-2391

Zane L, Ostellari L, Maccatrozzo L, Bargelloni L, Cuzin-Roudy J, Buchholz F, Patarnello T (2000) Genetic differentiation in a pelagic crustacean (Meganyctiphanes norvegica: Euhausiacea) from the North East Atlantic and the Mediterranean Sea. Mar Biol 136:191-199 